\title{
Siyasi Partilerin 2019 Yerel Seçimlerinde Web Sitesi Kullanımı ve Karşılaştırmalı Analizi
}

\author{
Website Use and Comparative Analysis of the Political Parties in 2019 Local \\ Elections
}

Emrah AR $\breve{G I N}{ }^{*}$

$\ddot{O} Z$

Kitle iletişim araçlarl; yasama, yürütme ve yargıdan sonra dördüncü bir güç olarak kabul görmektedir. Günümüzde en etkili ve yaygın kullanılan kitle iletişim aracı ise internettir. Internet ülkemizde siyasetçiler tarafindan yardımcı ve tamamlayıcı bir araç olarak sıklıkla kullanılmaktadır ve bundan sonra da kullanılmaya devam edecektir. Toplum üzerinde önemli etkisi olan internet medyası, Web 2.0'in gelişimiyle birlikte çift yönlü iletişime olanak tanıyan yapıya kavuşmuştur. Siyasi partiler, geleneksel kitle iletişim araçlarlyla birlikte, seçmenlerle etkileşim halinde olabilmek için internetin bütün imkânlarından faydalanmaktadır. Bu çalışmada, mecliste grubu bulunan AK PARTI, CHP, IYİ PARTI, MHP ve HDP'nin 31 Mart 2019 yerel seçimleri süresince kurumsal Web sayfaları karşılaştırmalı olarak analiz edilmektedir. Siyasi partilerin kurumsal Web sayfaları, işlevsellik ve tasarımsal özellikleri bakımından karşılaştırılarak değerlendirilmiştir. Içerik analizi yönetimi ile elde edilen bulgulara göre, Siyasi partilerin, kurumsal Web sayfalarını propaganda ve kamuoyunu bilgilendirme amacıyla sıklıkla kullandığı tespit edilmişstir.

\section{ANAHTAR KELIMELER}

Siyasi Partiler, Siyasal İletişim, Yerel Seçimler

\begin{abstract}
Mass media are regarded as a fourth power after the legislative, executive and judiciary. Today, the most effective and widely used mass communication tool is the Internet. The Internet is frequently used by politicians as an auxiliary and complementary tool in our country and will continue to be used thereafter. Internet media, which has a significant impact on the community, has acquired a structure that allows bidirectional communication with the development of Web 2.0. Together with traditional mass media, political parties benefit from the full range of internet opportunities to interact with voters. In this study, the corporate web pages are analyzed comparatively during the local elections of the AK PARTI, CHP, IYI PARTI, MHP and HDP which have a group in the parliament. The institutional Web pages of political parties were evaluated by comparing them in terms of their functionality and design features. According to the findings obtained with content analysis management, it was determined that political parties frequently used the corporate Web pages to inform propaganda and public opinion.
\end{abstract}

KEYWORDS

Political Parties, Political Communication, Local Elections

\begin{tabular}{|c|c|c|}
\hline \multicolumn{2}{|c|}{ Makale Geliş Tarihi / Submission Date } & \multicolumn{1}{c|}{ Makale Kabul Tarihi / Date of Acceptance } \\
07.03.2019
\end{tabular}

\footnotetext{
* Arş. Gör. Dr. Fırat Üniversitesi İletişim Fakültesi, Gazetecilik Bölümü, eargin@ firat.edu.tr, ORCID: 0000-0002-3619-8034
} 


\section{GíRiş}

1990'lı yıllardan itibaren hızla gelişen ve değişen internet teknolojisi günümüzde giderek genişlemiş ve farklı şekillerde kullanım imkanına kavuşmuştur. Bu yeni teknolojinin sunduğu iletişim imkanı klasik iletişim araçlarına göre iletişim sürecini tek yönlü olmaktan çıkarmış karşılıklı etkileşimi mümkün kılmıştır. İnternetin yaygınlık kazanmasıyla birlikte medyanın etkinlik alanı genişlemiş ve kullanıcılar içerik tüketen değil aynı zamanda içerik üreten bir aktör olma imkâna kavuşmuşlardır. İnternetin bilginin üretimi ve dağıtımı konusunda ortaya çıkardığı bu değişim siyasi partilerin ve aktörlerin de bu mecralarda yer almasını sağlamıştır.

Siyasi partiler sadece seçim dönemlerinde değil seçim dönemleri dışında da seçmenlerle iletişim halinde kalabilmek için internet sitelerini ve internetin sunduğu diğer araçları aktif halde kullanmaktadırlar. İnternet üzerine araştırmalar yapan ve küresel ölçekte faaliyet gösteren dijital pazarlama ajansı Wearesocial ${ }^{1} \operatorname{tarafindan}$ Ocak 2018'de yayımlanan "Digital in 2018 in Western Asia" adlı rapora göre, Türkiye nüfusunun yüzde 67'sinin (54.3 milyon) internet kullanıcısı olduğu ifade edilmektedir. Yüksek seçim kurulunun verilerine göre (YSK: 2019) 2017 Anayasa Referandumu'nda yaklaşık 48 milyon seçmen oy kullanmıştır. Bu verilerden yola çıkarak 2017 Anayasa referandumunda oy kullanan seçmenlerin yaklaşık yüzde 92'si aynı zamanda internet kullanıcısı olduğu söylenebilir. Bu durum siyasal iletişim bağlamında interneti önemli kılmaktadır.

Siyasi partiler herhangi bir medya kuruluşuna ihtiyaç duymadan istedikleri bilgileri istedikleri zamanda ve istedikleri şekilde aktarabilmek için web sitelerini sıklıkla kullanmaktadırlar. Medya kuruluşuna ihtiyaç duymadan bilgi akışının yönetilebilmesi ve anında iletişim imkanı sağlaması nedeniyle internet geleneksel kitle iletişim araçlarına göre daha avantajlı bir konumdadır. Bu bağlamda web sayfaları seçmenler ile siyasi partiler arasında bir aracı olmadan köprü işlevi sunmakta, seçmenlere geribildirim imkanı sağlamakta ve siyasi partilerin seçmene ulaşması açısından hızlı, güvenilir bir yol sağlamaktadır.

Siyasal iletişim, bilgilerin politikacılar ile seçmenler arasında medya aracılığıyla gerçekleşen interaktif bir süreçtir. Bu süreçte bilgi politikacılar tarafindan seçmenlere ve seçmenler tarafindan da politikacılara doğru bir bilgi akışı vardır. Siyasal iletişim bu kapsamda üç aşamadan oluşur. Birinci aşamada siyasal iletişim stratejilerinin tasarımı yapılır. Tasarlanan stratejilerin hayata geçirilmesi ise ikinci aşamayı oluşturur. Üçüncü ve son aşamada ise kampanya ile eş zamanlı olarak siyasal iletişim sürecinin etkisinin ölçümü yapılır (Çağlar ve Yusuf, 2015: 7). Burada esas amaç hedef kitlenin ikna edilerek arzu edilen şekilde oy verme davranışını ortaya koymalarını sağlamaktır.

$\mathrm{Bu}$ çalışmanın temel amacı partilerin kurumsal web sayfalarını seçim dönemlerinde ve genel olarak nasıl kullandıklarını ortaya koyarak, kullanım farklılıklarını tespit etmektir. Araştırmanın temel hipotezi 'Türkiye'de siyasi partiler tarafindan kurumsal web sayfaları seçim kampanyaları sürecinde aktif olarak kullanılmaktadır' şeklinde ifade edilmiştir. Bu bağlamda siyasi partilerin kurumsal web sayfaları incelenmiş ve web sayfaları işlevsellik ile tasarım özellikleri bakımından karşılaştırmalı olarak incelenmiştir.

\section{BİR KITLE ILETIŞIMM ARACI OLARAK INTERNETIN SIYYSAL PARTILER TARAFINDAN KULLANIMI}

Kitle iletişim araçlarının en önemli misyonu halkı doğru ve tarafsız bir şekilde bilgilendirmektir. İnternetle birlikte bilginin üretimi ve yayılması hiç olmadığı kadar hızlı bir şekilde gerçekleşmiş ve bilginin üretimi artmıştır. Bu durum internet teknolojilerinin merkezi olmayan özelliğinden kaynaklanmaktadır. Geleneksel kitle iletişim araçlarında, bilgiyi oluşturan ve kurgulayanın kendi politikaları çerçevesinde hareket edilirken yeni medyada bu kurgulamayı bilgiyi üreten ve iletene bırakmıştır. Başka bir ifadeyle internet teknolojisi sayesinde bireyler geniş bir kaynağa ve geniş bir kitleye ulaşabilme imkânına kavuşmuştur. Geleneksel kitle iletişim araçlarında yer almayan farklı görüşler ve fikirler internet medyasında rahatlikla yer alabilmektedir.

İnternet, dünyanın her yerinden birbirine bağlı ağlardan oluşan çağımızın teknoloji devrimi sayılmaktadır. $\mathrm{Bu}$ teknolojik gelişme her geçen gün sınırlarını arttırmakla kalmayıp içerik olarak da zenginleşmektedir (Arğın, 2018: 164). İnternet kullanımın artması, yeni web ortamlarının doğması ve bu yeni alanların giderek zenginleşmesini de beraberinde getirmiştir (Karabulut, 2012: 2). İnternet teknolojileri 1990'lı y1llarda seçim kampanyalarında ilk defa kullanılmaya başlanmıştır (Devran: 2003, 29). Özellikle web 2.0 gelişimiyle birlikte internetin seçim kampanyalarında kullanımı hız kazanmış ve seçim kampanyalarına interaktif bir iletişim imkanı sağlamıştır (Newman, 1999: 6). İnternet, günümüzde siyasi partiler ve seçmenler tarafindan en önemli siyasal iletişim aracı konumuna gelmiştir. Siyasi partiler interneti propaganda ve halkla ilişkiler amacıyla siklıkla kullanmaktadır.

İnternetin seçim kampanyalarında kullanım şekline baktı̆̆ımızda bireyler ve siyasal aktörler olmak üzere iki farklı boyutun karşımıza çıktığı gözlemlenmektedir. Bireyler açısından baktığımızda, siyasal içerikli

${ }^{1}$ Daha detaylı bilgi için; https://wearesocial.com/blog/2018/01/global-digital-report-2018. (Erişim Tarihi: 08.11.2018) 
bilgiler farklı kaynaklardan ulaşılabilir hale gelmiştir. Bu sayede enformasyonun tek elden yönetilmesi ihtimali ortadan kalkmıştır. Siyasi partiler açısından baktığımızda ise seçim kampanyaları dönemlerinde düşük bir maliyetle web sayfaları açmak ve bu sayfaları birer medya aracı gibi kullanmak, partiler için zaman ve maliyet açısından oldukça avantajlıdır (Beck, 2005: 27). Siyasi partiler açısından web sitelerinin enformasyonun kontrolünü sağlama açısından da oldukça önemi vardır. Bu sayede partiler istedikleri şekilde herhangi bir medya kuruluşuna bağlı kalmadan halkla ilişkiler ve propaganda faaliyetlerini yürütebilmektedirler.

Özellikle seçim dönemlerinde siyasi partiler seçmenlere ulaşabilmek için hızlı ve sansüre uğramamış, hacmi büyük bilgiyi seçmenlere ulaştırmaya çalışırlar (Schweitzer, 2005: 327-328). Siyasi partiler ve liderler siyaset arenasında yerlerini koruyabilme, daha iyi konuma gelebilme ve seçmenlerin dikkatini çekmek için günümüzde internetin sunduğu imkânlardan mümkün olduğunca faydalanmaya çalışmaktadır (Tokgöz, 2014: 11-17). Siyasi partilerin internette mecralarını kullanmalarının altı temel nedeni vardır. Bunlar (Gibson vd, 2003: 166-180):

- Geleneksel medyaya ve halka bilgi sağlamak,

- Kampanya yapıp bilgi verme - bağış toplama,

- Gençlere ulaşma,

- Modern bir parti imaji yaratma,

- Sanal dünyada tecrübe kazanma,

- Seçmenlerle etkileşimli olabilme amacı vardır.

Siyasi partiler tarafindan internet teknolojileri, kararsız seçmenin oyu olarak görülen "yüzen oylar"1 etkilemek içinde kullanılmaktadır. Hollanda'da 2002 yılında yapılan genel seçimlerinde, seçmenlerin kurumsal web sayfalarını ziyaret etme nedenlerini araştıran bir çalışmada, siyasi partilerin kurumsal web sayfalarının özellikle kararsız seçmenleri etkilemede oldukça başarılı olduğu sonucuna ulaşmıştır (Boogers vd., 2003: 20). Bu siteler sadece siyasal ilgisi yüksek kişilere değil, interneti yoğun olarak kullanan ancak siyasete uzak olan gençlere ulaşmayı da başarmaktadır. Kişiler daha çok, siyasal partilerin durumu, parti haberleri ve seçim kampanyasına ilişkin bilgi edinmede siyasi partilerin kurumsal web sayfalarını kullanmaktadır.

Kitle iletişim araçları, siyasi partilerin en sık kullandıkları ve kullanmak zorunda oldukları araçlardır. Partiler bu araçlar sayesinde seçmene ulaşarak seçmenin oy verme davranışını etkilemektedir. Partilerin seçmenler tarafindan algılanma şekli oy verme davranışını etkileyeceği için siyasal iletişim için en uygun zamanın ve en uygun kanalın seçilmesi oldukça önemlidir (Sancar, 2008: 54). Seçmenlere ulaşan siyasi partiler sadece seçmen tercihlerini değiştirmez, aynı zamanda seçmenleri oy vermeye ve kampanya içinde aktif olmaya da güdüler (Aydemir, 2013:137).

Siyasi partilerin geleneksel kitle iletişim araçlarında yer bulabilmeleri bütçeleriyle doğru orantılıdır. Siyasi partilerin seçim dönemindeki kampanyalarına uygun bütçeleri ile seçim çalışmaları için hazineden aldıkları yardımlar genellikle birbirine eşit değildir. Bu durumda bütçesi daha fazla olan partiler kitle iletişim araçlarında daha fazla yer almakta ve bütçesi az olan partilere göre daha etkin bir iletişim kampanyası yürütebilmektedirler. Bu eşitsizliği ortadan kaldıran, seçmen nezdinde küçük bütçeli partilerin de büyük bütçeli partilerle eşit düzeyde seçmenle iletişim kurabilmesini sağlayan partilerin web siteleridir (Alemdar ve Köker, 2011: 226-227). Başka bir ifadeyle siyasi partiler seçim kampanyalarını yürütebilmek için web sitelerini aktif olarak kullanmaktadır. Bu sayede bütçesi düşük olan partiler kurumsal web sayfalarını aktif ve işlevsel kullanarak seçim kampanyalarını yürütebilmektedir.

Türkiye'de internet teknolojilerinin siyasal iletişim amacıyla ilk defa 3 Kasım 2002 seçimlerinde kullanılmıştır. Bu dönemde bazı yeni teknolojilerin olduğu gibi internet de seçim kampanyası çalışmalarında sınırlı ölçüde kullanılmıştır. Siyasi partilerin büyük bir çoğunluğu 2002 seçimleri öncesinde web siteleri kullanmaktadırlar. Ancak sadece Anavatan Partisi, 3 Kasım 2002 seçimlerinde genç oylara da önem verdiği için özellikle siyasal partinin web sitesindeki faaliyetleri üzerine yoğunlaşmıştır. O dönemde Türkiye'de ki internet kullanımının yaygın olmamasından dolayı web siteleri üzerinden siyasal iletişim çalışmalarının geniş kitlelere ulaşamamıştır. Ancak bir sonraki dönemde yapılan 22 Temmuz 2007 Genel Seçimlerinde ise, siyasi partilerin web sitelerinin daha geniş kitlelere ulaştığı ve siyasal iletişim çalışmalarında kısmen de olsa işlevinin arttığı görülmüştür (Akt. Şener, 2018: 28).

Siyasal iletişim aracı olarak web sayfalarının kullanımı konusunu ele alan akademik çalışmalar incelendiğinde, araştırmaların odaklandıkları soruların; seçimlerde partilerin kurumsal web sayfalarının metinsel ile teknik içeriği üzerinde durulmuş ve karşılaştırmalı analizi yapılmıştır (Toruk, 2008; Alemdar ve Köker, 2011; Karlı ve Değirmencioğlu, 2011; Çağlar ve Köklü, 2017). Araştırmalarda siyasi partilerin siyasal iletişim amacıyla seçim dönemlerinde web sayfalarını aktif olarak kullandıkları sonucuna ulaşılmıştır. Evren ise (2015) yaptığı araştırmada 10 Ağustos 2014 tarihinde ilk kez halk oylamasıyla yapılan Cumhurbaşkanı 
seçimi öncesinde adayların web sayfalarını incelemiş ve Cumhurbaşkanı adaylarının, web sitelerini ağırlıklı olarak kendilerine ilişkin bilgileri yayma yönünde kullandıkları sonucuna ulaşmıştır.

Geleneksek kitle iletişim araçlarından farklı olarak internet teknolojileriyle hedef kitleye gönderilen mesaj tekrarlanabilmekte ve güncellenebilmektedir. Aynı zamanda internetin sağladığ ihtiyaç duydukları bilgilere çok kısa zamanda ulaşabilmekte ve karşılıklı iletişime geçebilmektedir. Yeni iletişim teknolojilerinin bu etkisi siyasal iletişim sürecini etkilemiş ve siyasetçileri daha şeffaf ve daha tutarlı olmaya zorlamıştır. İnternet sayesinde seçmenler, siyasi parti ve adaylar ile ilgili tüm bilgilere en kapsamlı ve en hızlı şekilde ulaşabilmektedir. Bu bilgiler seçmenlerin parti ya da aday hakkında olumlu veya olumsuz kanaat oluşturmasına ve oy verme davranışında etkili olmaktadır. Bu anlamda yeni iletişim teknolojilerini etkili ve verimli kullanan siyasi parti ve adaylar, seçmenleri etkileme imkanına sahiptir.

\section{YÖNTEM}

$\mathrm{Bu}$ araştırma ile 30 Mart 2019 yerel seçimlerine katılan siyasi partilerin kurumsal web sayfalarının karşılaştırmalı olarak incelenmesi amaçlanmaktadır. Araştırmanının evrenini 2019 yerel seçimlerine katılan AK PARTİ, CHP, İYI PARTİ, MHP ve HDP'nin kurumsal web sayfaları oluşturmaktadır. Çalışmanın evreni beş siyasal partiyle sınırlandırılmıştır. Bu sınırlandırmanın sebebi, mecliste grubu bulunan siyasi partilerin çalışmaya alınması ve bunun da temelinde bu siyasi partilerin yerel seçimler sürecinde daha yoğun bir kampanya yürüteceği düşüncesi yatmaktadır.

Araştırmada incelenen kurumsal web sayfalarının birbirlerinden farklı yönleri ve birbirleriyle olan benzerlikleri ortaya konularak, tasarım ve genel kurumsal bilgilendirme sağlayan içeriksel unsurlar incelenmiştir. Siyasal iletişim kampanyalarında kurumsal web sayfalarının kullanılmasının ve siyasi partiler tarafında kullanılan web sayfalarındaki farklılıkların değerlendirilebilmesi için içerik çözümlemesi yöntemi kullanılmıştır.

İçerik çözümlemesinde temel amaç toplanan verileri açıklayabilecek kavramlara ve ilişkilere ulaşmaktır. $\mathrm{Bu}$ amaçla toplanan verilerin önce kavramlaştııılması ve sonrasında ortaya çıkan kavramların mantıklı biçimde düzenlenmesi ve buna göre veriyi açıklayan temaların saptanması gerekmektedir (Akt. Arğın, 2018: 6). İçerik çözümlemesi bir anlamda toplanan verilere dayalı bir 'okuma' aracı olarak nitelendirilebilir. Bu okuma şekli, sınırları belirlenmiş söylem ve örneklerin çözümlenmesi esasına dayanmaktadır (Bilgin, 2006: 1).

\subsection{Kodlama Cetveli}

Siyasi partilerin kurumsal web sayfalarının kullanımı ve seçmene ulaşma şekilleri içerik analizi yöntemi ile incelenmiştir. Bu sayede web sayfalarını daha etkin kullanan siyasal parti nicel olarak tespit edilmeye çalışılmıştır. Çalışmada Cheng ve Schweıtzer'in (1996) "Cultural ValuesReflected inChınese and U.S.Televısıon Commercıals” skalası gözden geçirilmiş aynı zamanda Gibson ve Ward (2000)'ın “A Proposed Methodology for Studying the Function and Effectiveness of Party and Candidate Web Sites" adlı çalışmada kullandığ1 skaladan faydalanılmıştır. Bunun yanı sıra Gibson vd. (2003)'ın "Election Campaigning On The www In The USA And UK A Comparative Analysis", çalışması da incelenmiş ve kullanılan çeşitli ölçeklerden yararlanılmıştır. $\mathrm{Bu}$ araştırmanın içerik analizi kategorileri yukarıdaki çalışmalarda yer alan bilgilerden yararlanılarak oluşturulmuştur.

Çalışmadaki siyasi partilerin kurumsal web sayfalarının değerlendirme kategorileri ise İşlevsellik Özellikleri ve Tasarım Özellikleri olmak üzere iki başlıktan oluşmaktadır. Bu başlıklar şu şekilde alt kategorilere ayrılmıştır:

İşlevsellik Özellikleri: Basın Açıklamaları, Değerler/ İdeoloji. Politikalar, Dokümanlar, Aday Profilleri, Seçim Bilgileri, Arşiv, Üyelik, Bağış Toplama, Referans Linkleri, E-Mail, Forum, Site Haritası, Özel Seçim Sitesi, Broşür ve Propaganda Bilgilerinin İndirimi, Logonun İndirimi, Partinin Tarihçesi, E-bülten, Öneri/ Anket, İl ve İlçe Teşkilat Bilgileri ve Danışma Hattı başlıklı konular ele alınmıştır.

Tasarım Özellikleri: Grafikler, Hareketlilik / İmajlar, Ses, Video, Animasyon, Dokümanların Metin Halinde İndirilmesi ve Yazılması, Yabancı Dile Çeviri, Siteye Girişin Metin Halinde Sunulabilirliği, Görme Bozukluğu Olanlar İçin Yazılım, Site İçi Arama Motoru ve Haber Akışı başlıklı konular ele alınmıştır.

İçerik çözümlemesinde güvenilirlik kodlama sisteminin kullanılmasına bağlıdır. Güvenilirliğin sağlanabilmesi için kodlayıcıların ve kodlama kategorilerinin güvenilir olması gerekmektedir. Aynı kodlayıcıların aynı metni farklı zamanlarda büyük oranda aynı şekilde kodlamasını veya farklı kodlayıcıların aynı metni büyük oranda aynı şekilde kodlamalarını gerektirmektedir (Bilgin, 2006: 13). Bu şekildeki bir çalışma hata yapma olasılığının en aza indirilebileceği düşünülmektedir. Bu çalışmada kategori sistemleri; güvenilirliğin sağlanması amacıyla farklı zamanlarda farklı araştırmacılar tarafından iki kez kodlama yapılmış ve elde edilen bulgular birbiriyle büyük ölçüde (\% 99) uyumlu bulunmuştur. 


\section{BULGULAR ve YORUM}

Siyasi partilerin kurumsal web sayfalarının incelendiği bu bölümde işlevsellik ve tasarım özellikleri bakımından https://www.akparti.org.tr/, https://www.chp.org.tr/, https://iyiparti.org.tr/, https://www.mhp.org.tr/mhp_index.php ve https://www.hdp.org.tr/ web sayfaları karşılıklı olarak analiz edilmiştir.

\subsection{Siyasi Partilerin Kurumsal web Sayfalarının İşlevsellik Özellikleri}

Tablo 1: Siyasi Partilerin Kurumsal web Sayfalarının İşlevsellik Özellikleri

\begin{tabular}{|c|c|c|c|c|c|}
\hline \multicolumn{6}{|c|}{ İŞLEVSELLIKK ÖZELLİKLERİ } \\
\hline & $\begin{array}{c}\text { AK } \\
\text { PARTi }\end{array}$ & CHP & $\begin{array}{c}\text { iYi } \\
\text { PARTi }\end{array}$ & MHP & HDP \\
\hline Basın Açıklamaları & 1 & 1 & 1 & 1 & 1 \\
\hline Değerler ve İdeoloji & 1 & 1 & 1 & 1 & 1 \\
\hline Politikalar & 1 & 1 & 1 & 1 & 1 \\
\hline Dokümanlar & 1 & 1 & 1 & 1 & 1 \\
\hline Aday Profilleri & 0 & 0 & 1 & 0 & 0 \\
\hline Seçim Bilgileri & 1 & 1 & 0 & 0 & 1 \\
\hline Arşiv & 1 & 1 & 1 & 1 & 1 \\
\hline Üyelik & 0 & 1 & 1 & 1 & 0 \\
\hline Bağış Toplama & 0 & 1 & 1 & 0 & 0 \\
\hline Referans Linkleri & 1 & 1 & 0 & 1 & 1 \\
\hline E-Mail & 0 & 0 & 0 & 0 & 1 \\
\hline Forum & 0 & 0 & 0 & 0 & 0 \\
\hline Site Haritas1 & 1 & 1 & 0 & 0 & 0 \\
\hline Özel Seçim Sitesi & 0 & 0 & 0 & 0 & 0 \\
\hline Logonun İndirilebilmesi & 0 & 0 & 1 & 1 & 0 \\
\hline $\begin{array}{l}\text { Broşür ve Propaganda Bilgilerinin } \\
\text { İndirilebilmesi }\end{array}$ & 1 & 1 & 1 & 1 & 1 \\
\hline Parti Tarihçesi & 0 & 1 & 0 & 1 & 0 \\
\hline E-bülten & 1 & 1 & 1 & 1 & 1 \\
\hline Öneri ve Anket & 0 & 0 & 0 & 0 & 0 \\
\hline İl ve İlçe Teşkilat Bilgileri & 1 & 1 & 1 & 1 & 0 \\
\hline Danışma Hattı & 1 & 0 & 0 & 1 & 0 \\
\hline TOPLAM & 12 & 14 & 12 & 13 & 10 \\
\hline
\end{tabular}

Siyasi partilerin 2019 yerel seçimler döneminde kurumsal web sayfalarının işlevsellik özellikleri bakımından incelediğimizde Tablo 1'e göre ilgili web sayfaları birbirine benzerlik göstermektedir. İşlevsellik özellikleri bakımından en fazla özelliği CHP bulundururken en az özelliği ise HDP'nin web sayfası bulundurmaktadır. İncelenen siyasi partilerin kurumsal web sayfalarında Forum, Özel Seçim Sitesi ile Öneri ve Anket özelliklerini hiçbir parti kullanmamıştır. Basın Açıklamaları, Değerler ve İdeoloji, Politikalar, Dokümanlar, Arşiv, Broşür ve Propaganda Bilgilerinin İndirilebilmesi ve E-bülten işlevlerini bütün siyasi partiler kullanmaktadır. İl ve İlçe Teşkilat Bilgilerine HDP dışında bütün partiler yer vermiştir. Parti Tarihçesini sadece CHP ve MHP paylaşmıştır. AK PARTİ ve HDP kurumsal web sayfaları aracılığıyla üyelik kabul etmezken CHP, IYYİ PARTİ ve MHP kabul etmektedir. İncelenen çalışmalarda siyasi partiler daha önceki seçimlerde özel olarak ilgili seçim için web sayfası kullanırken 2019 yerel seçimleri için sadece partilerinin kurumsal web sayfalarını ve sosyal medyayı kullandıkları tespit edilmiştir. Partiler onaylanmış sosyal medya kanalları için bağlantı linkini paylaşmıştır. 
Web sitelerini interaktif hale getiren en önemli özellik öneri ve anket linklerinin olmasıdır. Görüldüğü üzere bu içerik hiç bir parti tarafından kullanılmamıştır. Dolayısıyla siyasi partilerin kurumsal web siteleri interaktif değildir. Web siteleri sadece bilgilendirme ve propaganda amaciyla kullanılmaktadır.

\subsection{Siyasi Partilerin Kurumsal web Sayfalarının Tasarım Özellikleri}

Tablo 2: Siyasi Partilerin Kurumsal web Sayfalarının Tasarım Özellikleri

\begin{tabular}{|c|c|c|c|c|c|}
\hline \multicolumn{6}{|c|}{ TASARIM ÖZELLIKLERI } \\
\hline & $\begin{array}{c}\text { AK } \\
\text { PARTi }\end{array}$ & CHP & $\begin{array}{c}\text { IYi } \\
\text { PARTi }\end{array}$ & MHP & HDP \\
\hline Grafikler & 1 & 1 & 1 & 1 & 1 \\
\hline Hareketlilik ve İmajlar & 1 & 1 & 1 & 1 & 1 \\
\hline Ses & 1 & 1 & 1 & 1 & 1 \\
\hline Video & 1 & 1 & 1 & 1 & 1 \\
\hline Animasyon & 0 & 0 & 0 & 0 & 0 \\
\hline Siteye Girişin Metin Halinde & 0 & 0 & 0 & 0 & 0 \\
\hline Sunulabilirliği & & & & & 1 \\
\hline Dokümanların Metin Halinde & 1 & 1 & 1 & 1 & 1 \\
\hline Indirilebilmesi ve Yazdırılabilmesi & & & & & \\
\hline Yabancı Dile Çeviri & 1 & 0 & 0 & 0 & 0 \\
\hline Görme Bozukluğu Olanlar İçin Yazılım & 0 & 0 & 0 & 0 & 0 \\
\hline Kullanım & & & & & 1 \\
\hline Site İçi Arama Motoru Kullanımı & 1 & 1 & 0 & 1 & 1 \\
\hline Haber Akışı & 1 & 1 & 1 & 1 & 1 \\
\hline
\end{tabular}

Siyasi partilerin 2019 yerel seçimler döneminde kurumsal web sayfalarının tasarım özellikleri bakımından incelediğimizde Tablo 2'ye göre ilgili web sayfaları birbirine benzerlik göstermektedir. Tasarım özellikleri bakımından en fazla özelliği AK PARTİ bulundururken en az özelliği ise İYİ PARTİ'nin web sayfası bulundurmaktadır. İYİ PARTİ site içi arama motoru özelliği sunmazken yabancı dile çeviri özelliğini sadece AK PARTİ'nin kurumsal web sayfası kullanmaktadır. AK PARTİ'nin kurumsal web sayfasına hem İngilizce hem de Arapça olarak ulaşılabilmektedir. Bu anlamda ülkede yaşayan yabancı uyruklu bireyler, AK PARTI dışında diğer partiler tarafindan dikkate alınmamaktadır.

Görme Bozukluğu Olanlar İçin Yazılım Kullanımı, Animasyon, Siteye Girişin Metin Halinde Sunulabilirlik özelliğini incelenen partiler içinde hiçbir parti web sayfası sunmamaktadır. İncelenen siyasi parti kurumsal web sayfalarının Grafikler, Hareketlilik / İmajlar, Ses, Video paylaşım özelliğini aktif olarak kullandıkları tespit edilmiştir.

\section{DEĞERLENDİRME ve SONUÇ}

Politik yaşamın vazgeçilmez bir unsuru olan seçimlerin yapılabilmesi ve siyasal katılımın arttırılabilmesi, çağdaş demokrasilerin önemli bir unsurudur. Modern toplumlarda siyasal iletişim çalışmalarının yürütüldüğü en önemli mecra kitle iletişim araçlarıdır. Son zamanlarda siyasal iletişim çalışmaları için en çok kullanılan mecra ise internet olmuştur. İnternet sayesinde bireyler kendileri arasında veya siyasi partilerle karşılıklı etkileşime dayalı iletişim kurabilmektedir.

Türkiye'de seçimlere katılım oranının yüksek olduğunu düşündüğümüzde siyasal iletişim sürecinin önemi artmaktadır. İnternetin Türkiye'de dünyada olduğu gibi siyasal iletişim çalışmalarında kullanılması oldukça yenidir. $\mathrm{Bu}$ yeni iletişim teknolojilerinin gücünün ve etkisinin fark edilmesi siyasi partileri bu mecraları kullanmaya sevk etmiştir. Türkiye'de internet siyasal iletişim çalışmalarında ilk defa 2007 genel seçimlerinde kullanılmış ve sonraki seçimlerde kullanımı artmaya devam etmiştir.

$\mathrm{Bu}$ çalışmada siyasi partilerin kurumsal web sayfaları yerel seçim içerikleri açısından incelenmiş ve web sayfaları 'İşlevsellik Özellikleri' ile 'Tasarım Özellikleri' olmak üzere iki ana başlıkta incelenmiştir. İşlevsellik 
özellikleri bakımından araştırmamızdaki ölçeğe göre en çok işlevsel özelliğe sahip olan CHP'nin kurumsal web sitesidir. Tasarım özellikleri bakımından ise araştırmamızdaki ölçeğe göre en iyi tasarıma sahip olan AK PARTİ'nin kurumsal web sitesidir.

Tasarım özellikleri bakımından incelenen siyasi partilerin web sayfaları birbirlerine benzerlik göstermektedir. AK PARTİ diğer siyasi partilerden farklı olarak kurumsal web sayfasında Yabancı Dilde siteyi kullanabilme imkânı sunmuştur. İncelenen diğer siyasi partilerde Yabancı Dilde siteyi kullanabilme imkânı sunulmamıştır. Site İçi Arama Motoru özelliğini ise sadece İYİ PARTİ kullanmamıştır. Diğer bütün siyasi partiler Site İçi Arama Motoru özelliğinden faydalanmaktadır. Genel olarak baktığımızda araştırma kapsamında incelenen kurumsal web sayfaları görünürde her ne kadar farklılıklar olsa da 'Isşlevsellik Özellikleri' ve 'Tasarım Özellikleri' bakımından oldukça benzerlik göstermektedir.

Araştırmanın temel hipotezi 'Türkiye'de siyasi partiler tarafindan kurumsal web sayfaları seçim kampanyaları sürecinde aktif olarak kullanılmaktadır' şeklinde ifade edilmiştir. Siyasi partilerin kurumsal web sayfası kullanımına genel olarak baktığımızda partiler, interneti aktif ve etkin bir şekilde kullandıkları söylenebilir. Bu anlamda araştırma hipotezimiz doğrulanmıştır. 


\section{KAYNAKÇA}

Alemdar, M. Y., \& Köker, N. E. (2011). Siyasi Partilerin 2007-2011 Türkiye Genel Seçimlerinde Web Sitesi Kullanımı ve Karşılaştırmalı Analizi. Erciyes Üniversitesi Sosyal Bilimler Enstitüsü Dergisi, 1(31), 225-254.

Arğın, E. (2018). İnternet Reklamlarına Karşı Tutumun Belirleyicileri: Otomobil Reklamları Örneği. International Journal of Social Science, 1 (1), 147-165. Retrieved from http://dergipark.org.tr/injoss/issue/37521/433568

Aydemir, E. (2013). Siyasal İletişimi Yeniden Okumak. İstanbul: Üçdal Neşriyat.

Beck, U. (2005). Siyasallığın İ́adı. (Çev.) Gürler, N. İstanbul: İletişim Yayınları.

Bilgin, N. (2006). Sosyal Bilimlerde İçerik Analizi: Teknikler ve Örnek Çalışmalar, (2. baskı), Ankara: Siyasal Kitapevi.

Boogers, M., \& Voerman, G. (2003). Surfing Citizens And Floating Voters: Results Of An Online Survey Of Visitors To Political Web Sites During The Dutch 2002 General Elections. Information Polity, 8 (1, 2), 17-27.

Cheng, H., \& Schweitzer, J. C. (1996). Cultural values reflected in Chinese and US television commercials. Journal of advertising research, 36(3), 27-46.

Çağlar, İ., \& Özkır, Y. (2015, May). Türkiye'de Siyasal İletişim: 2007-2015. SETA.

Çağlar, N, Köklü, P. (2017). Yeni Medyanın Siyasal İletişim Aracı Olarak Kullanımı: Siyasal Partilerin Resmi Web Sitelerine Yönelik Bir Araştırma. Gümüşhane Üniversitesi İletişim Fakültesi Elektronik Dergisi, 5 (1), 148-173. DOI: 10.19145 /gumuscomm.277833

Devran, Y. (2003). Siyasal Kampanya Yönetimi: Mesaj. Strateji ve Taktikler, AND Yayınları, İstanbul.

Evren, F. (2015). Bir Siyasal İletişim Aracı Olarak İnternet Sitesi Kullanımı: 2014 Cumhurbaşkanı Seçimi. Journal of Yaşar University, 10 (39), 6555-6565. Retrieved from http://dergipark.org.tr/jyasar/issue/19153/203357

Gibson, R. K., Margolis, M., Resnick, D., \& Ward, S. J. (2003). Election Campaigning on the WWW in the USA and UK: A Comparative Analysis. Party Politics, 9(1), 47-75.

Gibson, R., \& Ward, S. (2000). A Proposed Methodology For Studying The Function And Effectiveness Of Party And Candidate Web Sites. Social science computer review, 18(3), 301-319.

Karabulut, A. (2012). Ortaöğretim Öğrencilerinin İnternet Tüketimlerindeki Görsel Tasarım Algılarının İletişimsel Rolüne İlişskin Görüşleri: Elazığ Örneği. Yayımlanmamış Yüksel Lisans Tezi, Fırat Üniversitesi, Sosyal Bilimler Enstitüsü, İletişism Bilimleri Anabilim Dalı, Elazı̆̆.

Karlı, İ, Değirmencioğlu, G. (2011). Siyasal İletişim Açısından Siyasal Partilerin İnternet Mecrasından Yararlanma Biçimleri Ve Karşılaştırmalı Bir Analiz. Marmara İletişim Dergisi, (18), 141-161. Retrieved from http://dergipark.org.tr/maruid/issue/25223/266794

Newman, B. I. (1999). The mass marketing of politics: Democracy in an age of manufactured images. Sage Publications.

Sancar, G. A., (2008). Siyasi Parti İmajının Oluşmasında Medyanın Rolü. Marmara Üniversitesi Sosyal Bilimler Enstitüsü Yayınlanmamış Yüksek Lisans Tezi, İstanbul.

Şener, Y. (2018). Siyasal Partilerin Halkla İlişkiler Çalışmaları ve Seçmen Memnuniyeti: Elazı̆̆ İli Örneği.Yayımlanmamış Yüksel Lisans Tezi, Frrat Üniversitesi, Sosyal Bilimler Enstitüsü, İletişsim Bilimleri Anabilim Dalı, Elazığ.

Schweitzer, E. J. (2005). Election campaigning online: German party websites in the 2002 national elections. European Journal of Communication, 20(3), 327-351.

Tokgöz, O., (2014). Siyasal İletişimi Anlamak, 2. Baskı, İmge Kitabevi, Ankara.

Toruk, İ . (2013). 22 Temmuz 2007 Genel Seçimlerinde Siyasal Partilerin İnternet Sitelerine Bir Bakış. Selçuk Üniversitesi İletişim Fakültesi Akademik Dergisi, 5 (2), 219-234. Retrieved from http://dergipark.org.tr/josc/issue/19016/200716

Yüksek Seçim Kurulu, Halk Oylaması Sonuçları, <http://www.ysk.gov.tr/ysk/halkoylamasi-arsivi/2648 > 31.03.2019. 